Article

\title{
A Case-Study of Sustainable Countermeasures against Shallow Landslides in Central Italy
}

\author{
Diana Salciarini ${ }^{1, *,+}$, Evelina Volpe ${ }^{2, \dagger}$, Ludovica Di Pietro ${ }^{1, \dagger}$ and Elisabetta Cattoni ${ }^{3, \dagger}$ \\ 1 Dipartimento di Ingegneria Civile e Ambientale, Università degli Studi di Perugia, 06125 Perugia, Italy; \\ dipietroludovica@gmail.com \\ 2 National Research Council of Italy, Research Institute for Geo-Hydrological Protection, 06128 Perugia, Italy; \\ evelina.volpe@irpi.cnr.it \\ 3 Department of Civil and Environmental Engineering, eCampus University, via Isimbardi 10 Novedrate (CO), \\ 22060 Novedrate, Italy; elisabetta.cattoni@uniecampus.it \\ * Correspondence: diana.salciarini@unipg.it \\ + These authors contributed equally to this work.
}

Received: 4 March 2020; Accepted: 29 March 2020; Published: 6 April 2020

check for updates

\begin{abstract}
Traditional technical solutions for slope stabilization are generally costly and very impacting on the natural environment and landscape. A possible alternative for improving slope stability is based on the use of naturalistic engineering techniques, characterized by a low impact on the natural environment and being able to preserve the landscape identity and peculiarities. In this work, we present an application of such techniques for slope stabilization along a greenway located in central Italy, characterized by an extraordinary natural environment. First, 22 potentially unstable slopes have been identified and examined; then, among these, two standard type slopes have been selected. For both of them, an appropriate naturalistic engineering work has been proposed and stability analyses have been carried out. These have been performed by considering different piezometric conditions and using two different approaches: (a) a classical deterministic approach, which adopts deterministic values for the mechanical properties of the soils neglecting any uncertainty, and (b) a probabilistic approach that takes into account a statistical variability of the soil property values by means of their probability density functions (PDFs). The geometry of each slope derives from a digital model of the soil with 1 meter resolution, obtained through Light Detection and Ranging (LiDAR) survey provided by the Italian Ministry of the Environment. The soil mechanical characteristics and their PDFs are derived from the geotechnical soil property database of the Perugia Province. Results show an increase in slope stability produced by the adopted countermeasures measured in terms of Factor of Safety $\left(F_{s}\right)$, Probability of Failure (PoF) and efficiency.
\end{abstract}

Keywords: naturalistic engineering; slope stability; probabilistic analyses

\section{Introduction}

In many Italian areas the geological, geomorphological, and hydrographic features lead to a significant landslide susceptibility, mainly caused by intense or persistent rainfalls $([1,2])$. The traditional countermeasures adopted to mitigate rainfall-induced landslide risk often produce high impacts on landscape and are typically very costly. Thus, technically and economically sustainable solutions are needed to preserve the environmental heritage of many Italian areas, and at the same time, provide efficient and trustworthy stabilization works. Naturalistic engineering is a relatively young discipline including techniques of re-naturalization; anti-erosion and stabilization of shallow covers; and, as defined in [3], it involves the use of all plant species, whether represented by a single plant or a set of plants, considered as any other engineering building material. To rationally apply the naturalistic 
engineering methods to mitigate landslide risk, it is important to understand some important effects due to the presence and the role of vegetation on slope. First, vegetation dissipates most of the kinetic energy of raindrops, weakening the erosion action. The degree of interception depends on the density of the leaves and the size of the plant. From the geomechanical and stabilization point of view, the most important effect is the mechanical reinforcement exerted by the roots, analyzed by different authors (see, e.g., in [4-9]). This consists of an increase in the shear strength of vegetated soil, which is typically included in the Mohr-Coulomb failure criterion as additional soil cohesion $([10,11])$. Examples of naturalistic engineering applications are described in, e.g., [12] where the authors show the stabilization of a series of cases histories of shallow slopes instabilities located in Campania (Italy) by means of naturalistic works. Another example of application is introduced in [13], where the naturalistic stabilizations of a road escarpment in Umbria and a dam reservoir in Sardinia (Italy) are described.

In this work, we present the application of countermeasures based on naturalistic engineering techniques for the stabilization of slopes along a greenway in central Italy. Here, 22 potentially unstable slopes are examined, then two standard types are selected to analyze the stability variation based on the proposed naturalistic engineering works. The stability analyses are conducted both considering the soil properties deprived of any uncertainty (deterministic approach), both adopting a possible variability of their values to handle the issue of reliability of soil data that characterize the cover ([14-16]). In this second case, a different level of complexity to include the uncertainty in the measurements is possible: a simple parametric approach, where the soil mechanical properties are varied in a given range; or a probabilistic approach, where the input data are assigned as random variables, characterized by specific probability density functions (PDFs). In the deterministic and parametric approach the safety level of the slope is evaluated by means of a single synthetic parameter called Safety Factor $F_{S}$ (representing the ratio between the available resistance and the driven actions), while in the probabilistic approach the safety level of the slope is expressed through the Probability of Failure (PoF), i.e., the probability that $F_{s} \leq 1$ ([17]).

The aim of this contribute is to quantitatively evaluate the effectiveness of sustainable countermeasures, adopting rational and differentiated approaches that, although based on simplifying hypotheses, are able to provide an assess of the increase of the slope level of safety produced by such works. Also, in this work, we cope with the problem of model reliability by associating a probabilistic evaluation of the $F_{S}$ to a more traditional, deterministic one.

The paper is organized as follows. Section 2 outlines the study area. The deterministic and probabilistic approaches considered in the stability analyses are summarized in Section 3. Section 4 provides the details of the stability analyses performed, whereas Section 5 describes some selected results of the numerical simulations. Finally, Section 6 concludes with a discussion of the results and some remarks.

\section{The Study Area}

The examined area is located in central Italy in the district known as Valnerina, and includes the track of the former Spoleto-Norcia railway, historical masterpiece of railway engineering, today converted to greenway. This area is highly susceptible to different kinds of instabilities: rockfalls, rocksliding, and shallow landslides (Figure 1).

The Spoleto-Norcia railway, realized in 1926, at that time was an example of infrastructure that remains as a monument. The railway was considered an impressive engineering work, surrounded by a natural scenario of mountains Figure 2.

In the 1960s, due to the low number of travelers, the railway line was abandoned. At the beginning of the new millennium, the former railway was converted in a greenway, a communication path reserved exclusively for non-motorized travelers, developed in an integrated way that improve both the environment and the quality of life in the surrounding area. 
Unfortunately, after the central Italy earthquake of August and October 2016, some sectors of the greenway were closed because of the significant landslide risk along the track. For the reopening, countermeasures that grant a reduction of the risk and the protection of landscape are desirable.

The study area is located to the southeast of the Umbria region. The digital elevation model of the area shows a mainly mountainous territory with elevations ranging from $400 \mathrm{~m}$ to $800 \mathrm{~m}$ over the sea level. The area is characterized by slope angles varying from $5^{\circ}$ to $50^{\circ}$ with the highest values in the central part of the study area. The soil rock formations outcropping at the ground surface, according to the classification described in [18], are covered by landslide deposits of different thicknesses. After intense or prolonged rainfall, the soil covers are subject to shallow landslide reactivations.

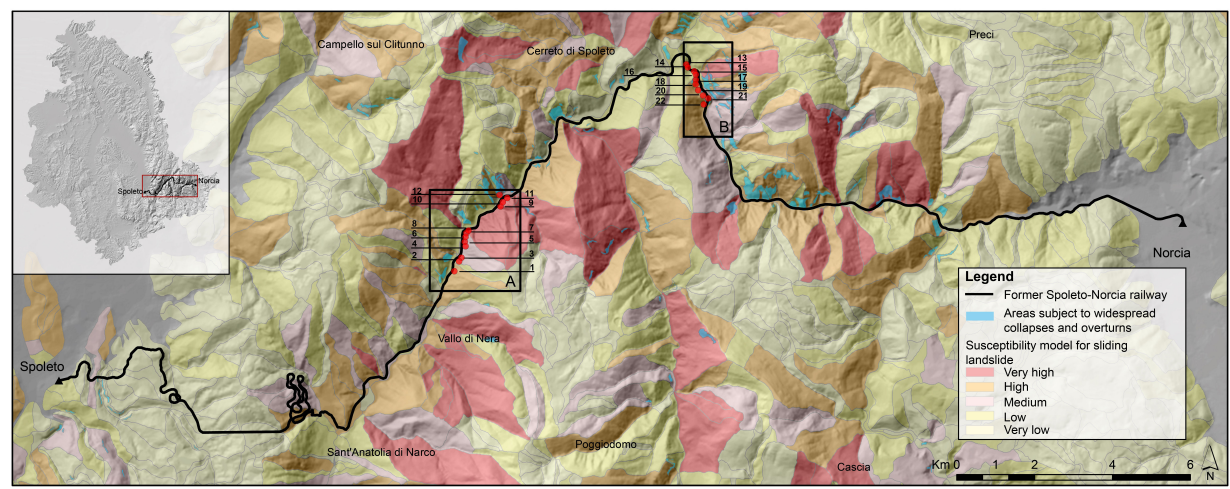

Figure 1. Map of landslide susceptibility with location of study area (black squares).
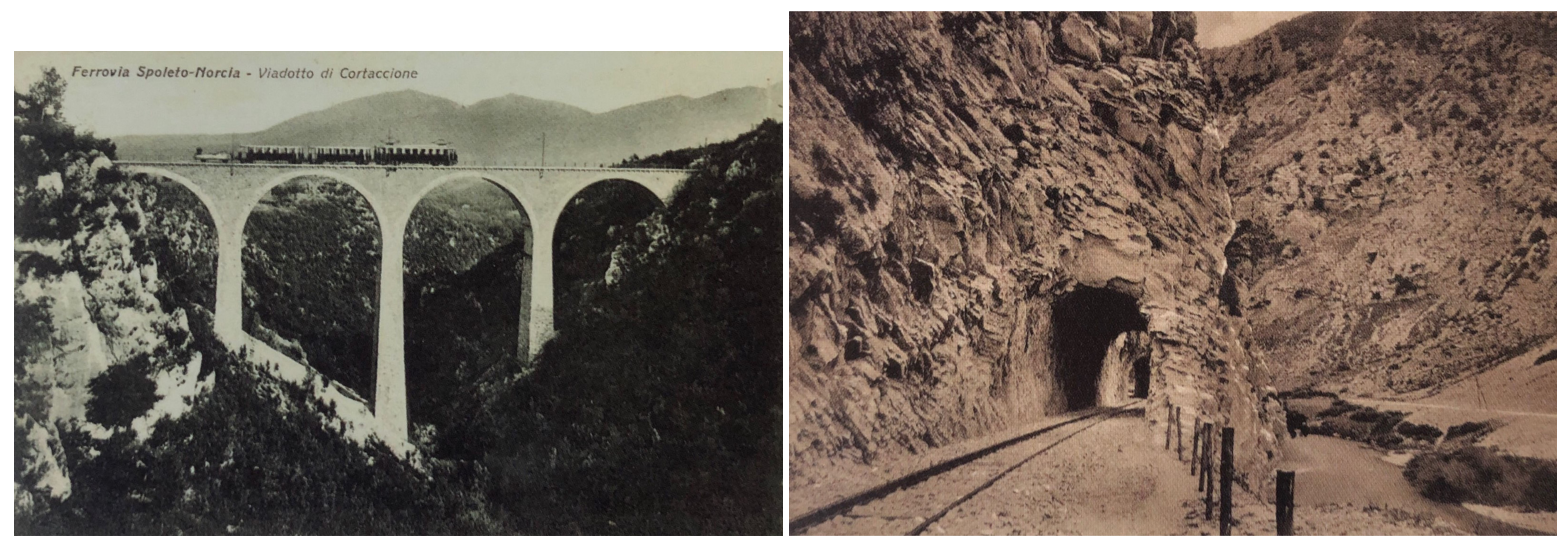

Figure 2. Examples of work along the track: viaduct and tunnel (courtesy by Umbriamobilita SpA.

For a first analysis and description of the main peculiarities of the study area, the available territorial information have been integrated in a Geographic Information System (GIS) environment. Namely, the following cartography has been collected; (a) Landslide Inventory Map derived from the so-called IFFI Project ([19]), containing localization, classification, volume, propagation distance, and state of activity of landslides; (b) Hydrogeological strategy plan (derived from the so-called PAI project), including localization, classifications, and landslide areas; (c) Landslide Map by the CNR-IRPI, synthesis of numerous studies carried out by means of aerial photos and direct surveys since the early 1950s; (d) Susceptibility map for landsliding (Figure 1); (e) Geological map.

The map of Figure 3 integrates must of such information [20], showing the susceptibility of the territory (classified from very low to very high), along with the location of inventoried landslides. From technical reports by the management of the greenway (Umbria Mobilità SpA), the triggering causes of landslides in the study area have been individuated, namely, most of the rockfall events are induced by earthquakes, whereas shallow landslides are mostly induced by rainfall and variation of the water table levels $([21,22])$. To characterize the study area from the physical and mechanical point of view, technical reports of previous in situ surveys and lab tests have been collected $([23,24])$. For the 
probabilistic characterization of the soil mechanical properties, the database of the Perugia Province by [18] is available.

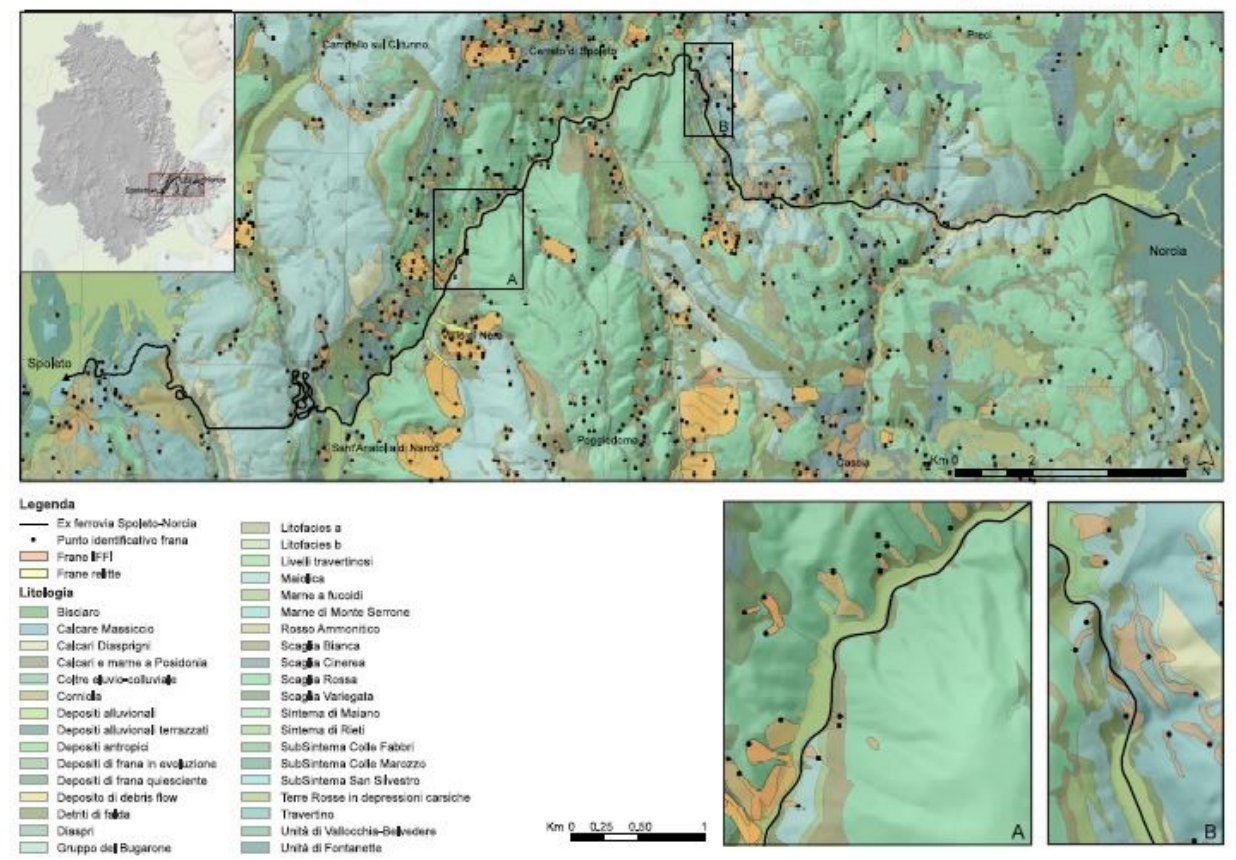

Figure 3. The greenway Spoleto-Norcia, the location of the slopes analyzed, and the soil types in the study area. The black dots represent the landslide points recorded in the IFFI project.

\section{Methodology}

To examine the unstable slopes, to propose naturalistic engineering works, and to evaluate the performance of such countermeasures, the following procedure has been adopted.

- First, a detailed analysis of 22 potentially unstable slopes with direct investigations and in-situ surveying has been done. For each slope shown in Figure 1 a table-sheet has been created, which includes photographic documentation, location, and information on the area (Figure 4).

- Secondly, two standard type slopes have been selected, chosen as prototypes for guiding the adoption of the correct work in other parts of the track.

- Finally, stability analyses before and after the proposed countermeasures have been carried out to quantify the performance of the works. 


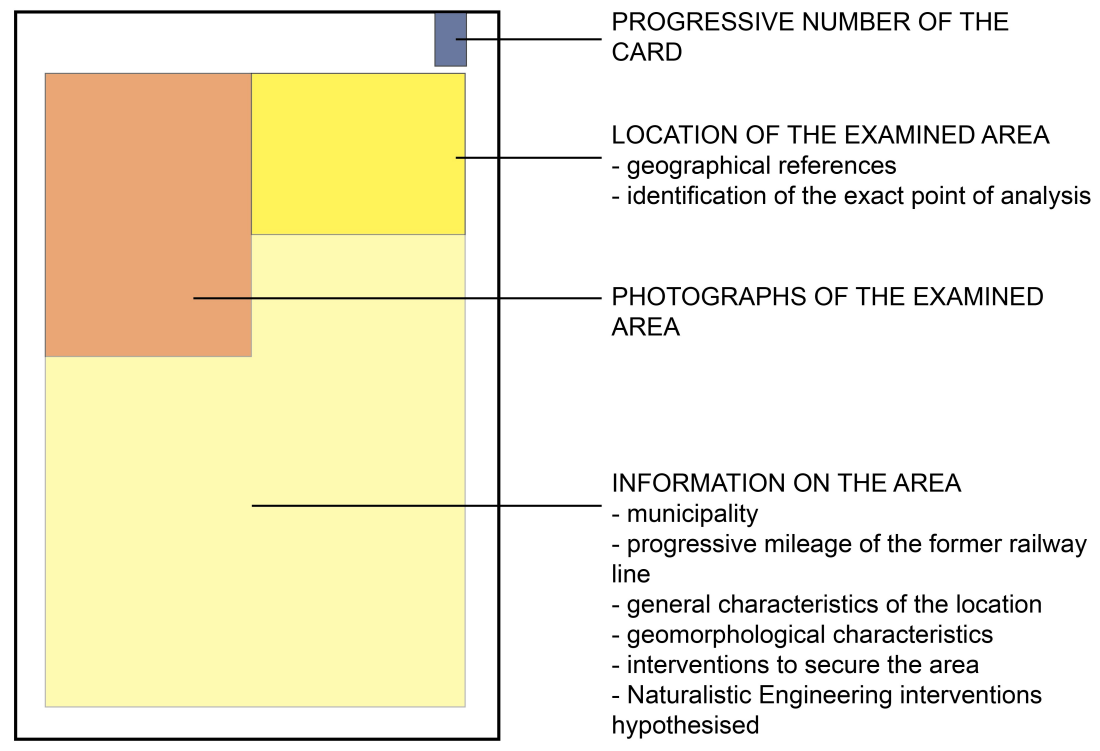

Figure 4. Example of sheet with synthetic information on studied slope.

\section{Stability Analysis}

\subsection{Deterministic and Probabilistic Approaches}

In a deterministic approach, the stability analyses, which can be carried out with classical limit equilibrium methods, quantify the safety level of a slope by a single scalar quantity, the Factor of Safety $\left(F_{s}\right)$, computed as the ratio between the available shear strength and the mobilized shear stress along a potential failure surface. The shear strength can be computed as

$$
\tau_{f}=c+\left(\sigma_{n}-u\right) \tan \phi
$$

where $\sigma_{n}$ is the normal total stress acting on the failure surface; $u$ is the pore water pressure; and $c$ and $\phi$ are the effective cohesion and friction angle of the soil, respectively.

However, the triggering process of a landslide phenomenon is characterized by different sources of uncertainty, totally ignored by the deterministic models [25]. Typically, these uncertainties are due to (i) measurement errors in the geotechnical soil characterization, (ii) hypothesis of the mathematical model used to describe the phenomenon, and (iii) spatial variability of the mechanical characteristics of the soil. Evaluating rainfall-induced landslide hazard with deterministic approaches does not provide a measure of the uncertainty of the slope stability assessment. The uncertainty of the quantities involved can be considered by means of a probabilistic approach in which the input quantities are assumed as random variables, characterized by a probability density function (PDF). The safety level of the slope is then evaluated as the Probability of Failure (PoF), i.e., the probability that $F_{s} \leq 1$. In this case, the strength parameters can be assigned with their probability distribution (log-normal for the cohesion and normal for the friction angle). The Monte Carlo scheme is then used to compute a probability distribution of the resulting safety factors. The stability analyses have been carried out using Slope/W code [26] and selecting the Morgenstern \& Price approach [27] among the Limit Equilibrium Methods. The used code allows to analyze both simple and complex problems for soil and rock slopes, for a variety of slip surface shapes, pore-water pressure conditions, soil properties, and loading conditions, including a general comprehensive algorithm for probabilistic analyses. 


\subsection{Study-Slopes}

Based on the preliminary analyses of 22 slopes and summarizing the classification and the description of stabilization work hypotheses, two slope profiles along the greenway Spoleto-Norcia are selected and assumed as reference sections. The profile of each slope was derived from the digital terrain model (DTM) of 1 meter resolution, obtained by LiDAR survey by the Italian Ministry of the Environment.

The two considered slopes are shown in Figure 5 (Slope S1) and Figure 6 (Slope S2). Figure 7 is a zoomed view of a portion of the Spoleto-Norcia greenway with the location of the sections S1 and S2 considered for the Limit Equilibrium Method (LEM). analyses.

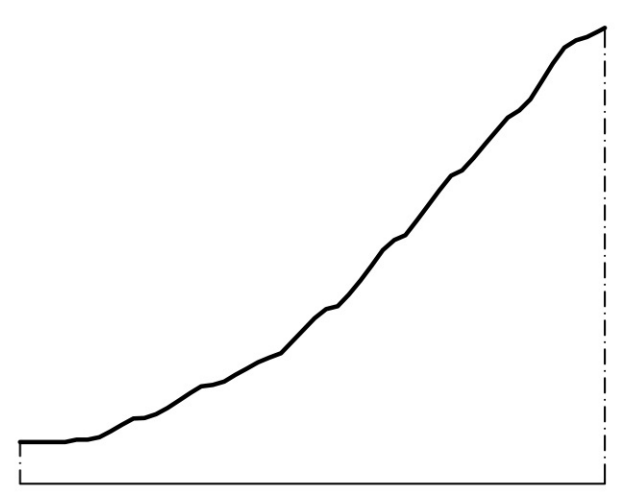

(a)

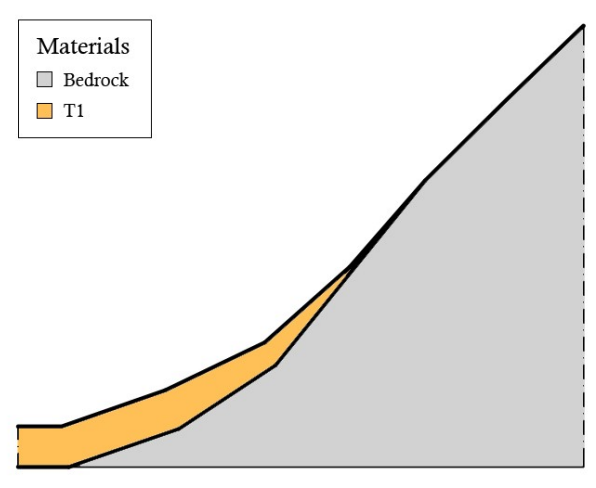

(b)

Figure 5. The calculation profile considered in the stability analysis for S1.

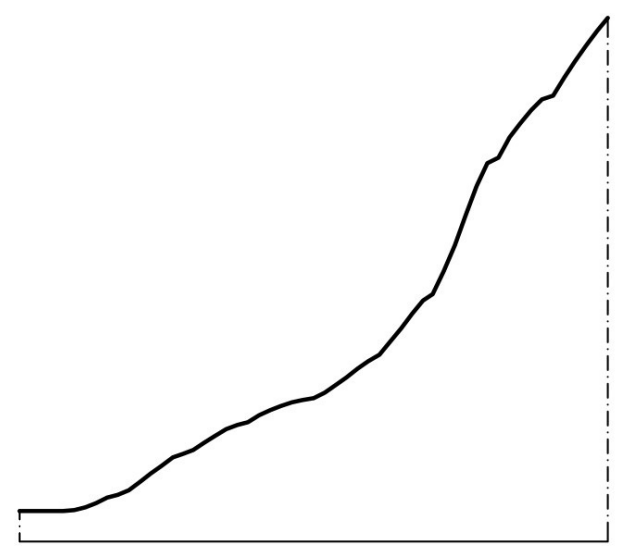

(a)

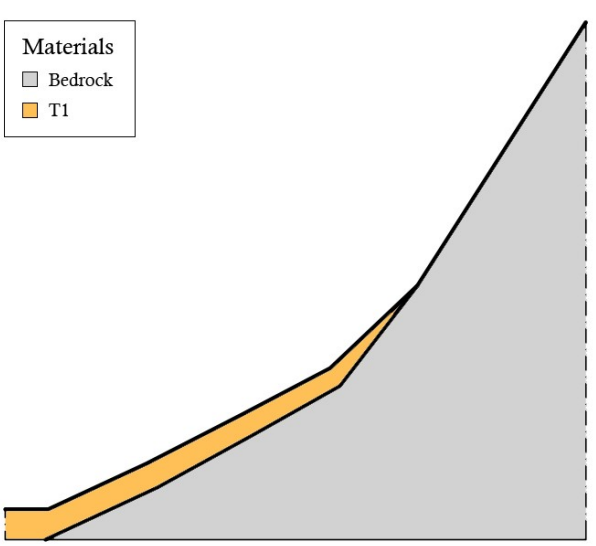

(b)

Figure 6. The calculation profile considered in the stability analysis for S2. 


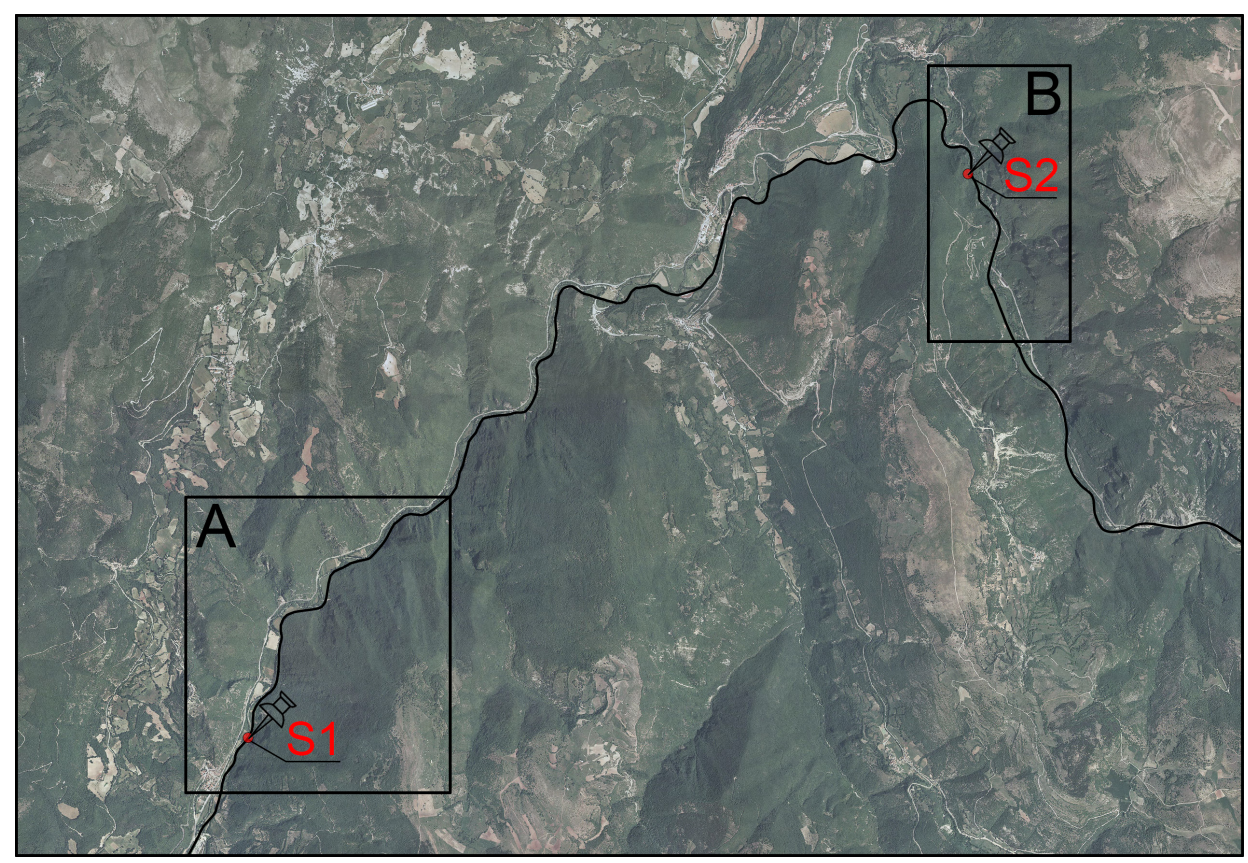

Figure 7. Zoomed view of a portion of the green way Spoleto-Norcia, with the location of the sections S1 and S2 considered for the LEM analyses.

Both the slopes S1 and S2 have a similar stratigraphy, characterized by two lithologies: a superficial soil cover, constituted by landslide deposits, overlying a relatively impervious bedrock. The slope S1 has a more limited inclination and a soil cover with a maximum thickness approximately equal to 3.70 . The slope S2 is steeper and the soil cover has with a maximum thickness of approximately $2.80 \mathrm{~m}$. The thicknesses of the covering layer derive from in situ surveys that show a good agreement with the estimated values by the law proposed for central Apennines area by [28]:

$$
d_{b}=\left\{\begin{array}{rr}
14 \exp (-0.07 \alpha) & d_{b} \geq 1 \mathrm{~m} \\
1 \mathrm{~m} & d_{b}<1 \mathrm{~m}
\end{array}\right.
$$

with $d_{b}=$ thickness of the covering layer and $\alpha=$ slope angle.

For each slope two different water table conditions have been considered: (i) no water: the piezometric line is located at the upper boundary of the bedrock; (ii) presence of water: the piezometric line is located at the upper boundary of the shallow covering (most critical condition).

\subsubsection{Soil Properties—Deterministic Approach}

The soil properties adopted in this study are the result of geotechnical tests, carried out independently on this work, and technical reports available for the study area. The mechanical properties used to describe the in situ soil cover material $\mathrm{T} 1$ are summarized in Table 1.

Table 1. Deterministic properties for soil cover before (T1) and after (T2) stabilization works.

\begin{tabular}{cccc}
\hline & $\gamma\left(\mathbf{k N} / \mathbf{m}^{3}\right)$ & $\mathbf{c ~ ( k P a )}$ & $\boldsymbol{\phi}\left({ }^{\circ}\right)$ \\
\hline $\mathrm{T} 1$ & 18 & 5 & 28 \\
$\mathrm{~T} 2$ & 20 & 10 & 35 \\
\hline
\end{tabular}

\subsubsection{Soil Properties—Probabilistic Approach}

Following the probabilistic approach, the slopes properties have been evaluated integrating the in situ data measures with data derived from a large soil database, available for the Perugia Province. The georeferenced database is the result of a research that involved the Structural Control and Civil 
Protection Office of the Perugia Province and the Department of Civil and Environment Engineering of the University of Perugia. Most of the mechanical parameters were estimated by static and dynamic penetrometer tests and by laboratory tests. For landslide deposits, the geotechnical parameters (effective cohesion and effective friction angle) have been obtained starting from 204 collected measures. The procedure used for the stochastic characterization, based on the Pearson test, is described in detail in $[18,29]$; the soil properties used for the slopes S1 and S2 are summarized in Table 2, in terms of mean values and coefficients of variation (COV). The values of $\mathrm{COV}$, that are a standardized measure of dispersion of a probability distribution or frequency distribution, are directly derived from the collected measures. The choice of COV values means that the cohesion reachs a maximum value of $10 \mathrm{kPa}$, whereas the $\phi$ value varies between approximately $18^{\circ}$ and $38^{\circ}$.

Table 2. Stochastic properties for in situ soil cover.

\begin{tabular}{cccc}
\hline & pdf & Mean Value & COV \\
\hline $\mathrm{c}$ & log-normal & $5[\mathrm{kPa}]$ & 0.23 \\
$\phi$ & normal & $28\left[^{\circ}\right]$ & 0.07 \\
\hline
\end{tabular}

\section{Proposed Countermeasures}

To increase the stability conditions of the considered slopes and reduce the hazard along the greenway, two different types of works have been hypothesized. For the slope S1, the construction of a double-walled wooden piling is considered. This work creates a modification of the slope profile at the base, due to the realization of the structure, and a re-profiling of the slope performed with backfilling material. A comparison between the original aspect of the slope and the aspect after the installation is shown in Figure 8 by means of a photographic rendering of the work. In the calculation model, the countermeasure realization can be accounted by adding a volume of soil at the end of the slope, which includes the structural wooden part and the grass cover; the calculation scheme adopted is shown in Figure 9.

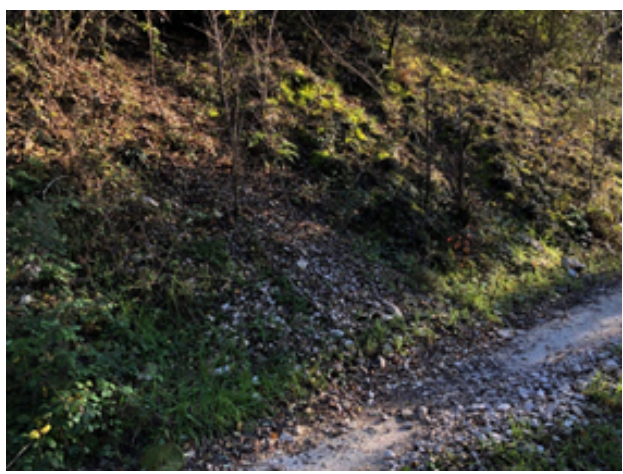

(a)

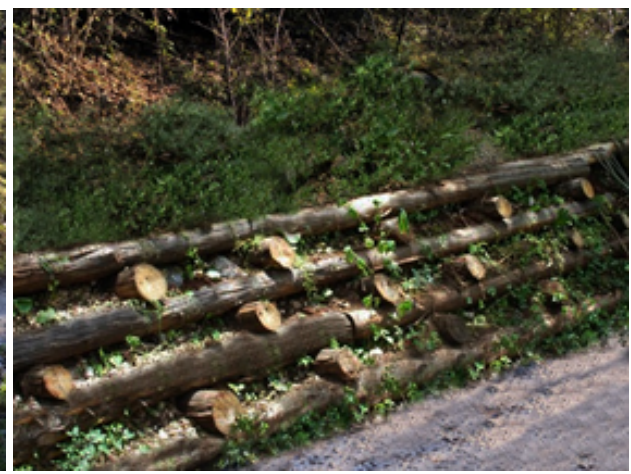

(b)

Figure 8. Simulated naturalistic work for S1 through photographic rendering: (a) initial condition of slope and (b) condition after naturalistic work realization. 


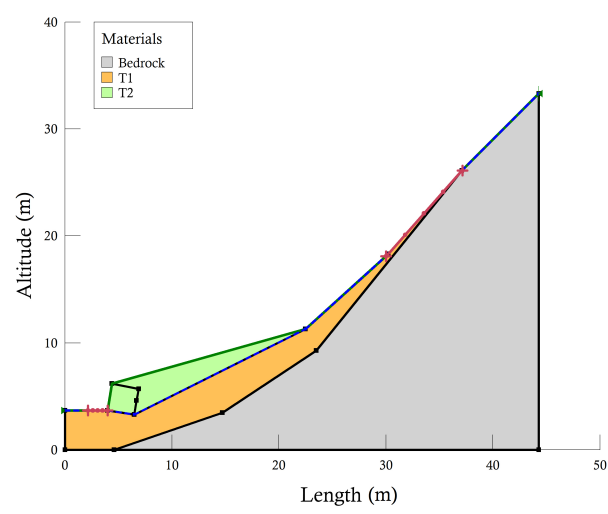

Figure 9. Model used to simulate the presence of the double-walled wooden piling.

This new geometry considers the actual work dimensions, whereas the presence of grass cover and vegetable materials is considered through modified soil mechanical properties indicated as T2 (Tables 1 and 3). The properties of the soil cover (T2) have been chosen considering a coarse-grained covered with grass. Compared to in situ soil, T2 is characterized by higher friction angle and cohesion due to the grass roots mechanical effect, according to $[8,10,11]$.

Table 3. Soil properties for the cover used in the probabilistic analyses.

\begin{tabular}{cccc}
\hline & pdf & Mean Value & COV \\
\hline $\mathrm{c}$ & log-normal & $10[\mathrm{KPa}]$ & 0.2 \\
$p h i$ & normal & $35\left[^{\circ}\right]$ & 0.06 \\
\hline
\end{tabular}

For slope S2, a stockade installation has been considered. Its realization requires the removal of part of the soil cover, and then the positioning and insertion of plants that realize a uniform cover grass. The changed in the slope aspect is shown in Figure 10 by means of a photographic simulation compared with the original state of the slope.

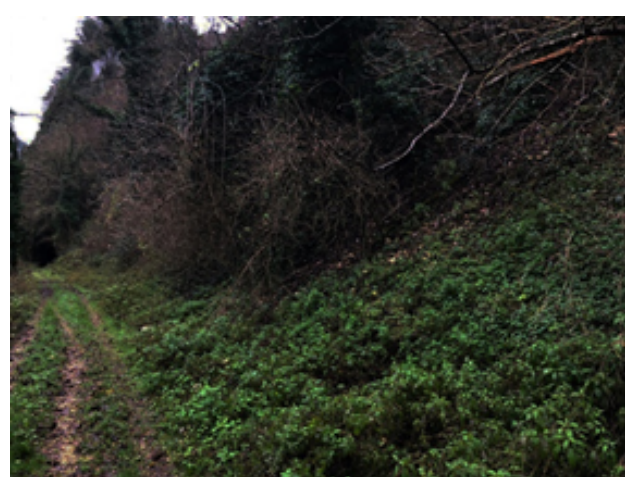

(a)

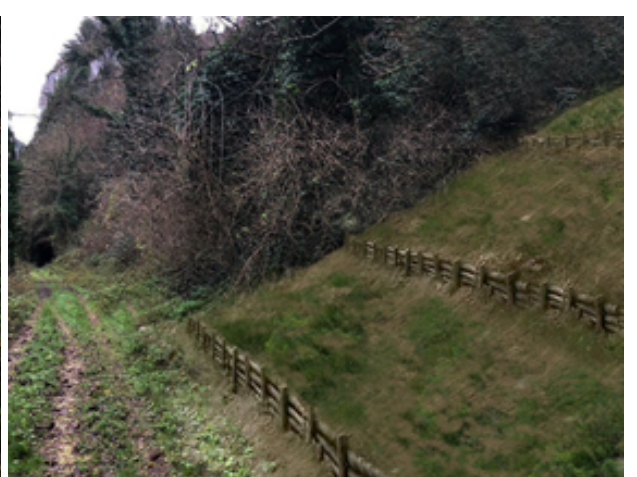

(b)

Figure 10. Simulated naturalistic work for S2 through photographic rendering: (a) initial condition of the slope; (b) condition after naturalistic work realization.

The work does not significantly modify the slope geometry but introduces additional shear strength due to the roots of the grass cover and the vertical constraining elements, which can be schematized as small wooden piles with a diameter of $0.15 \mathrm{~m}$. The mechanical properties used for the soil T2 are the same as in Tables 1 and 3; the computational model adopted is shown in Figure 11. 


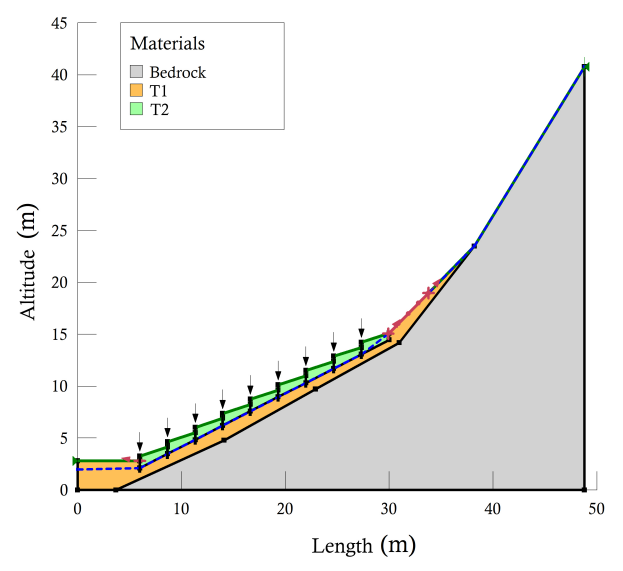

Figure 11. Model used to simulate, on slope S2, the presence of stockade.

From a general point of view, the two naturalistic works improve the mechanical properties of the soil in the same way; however, the environmental impact generated by the naturalistic measurements is different. In particular, the work on S1 creates a wooden grid on the intervention area, while the stockade work on S2 is less impacting on the slope aspect, intervening with thinner wooden piles arranged in rows. The choice of the naturalistic interventions has been made considering the specific environment context.

\section{Results}

The stability analyses of the studied slopes were carried out comparing the original conditions of the slopes (natural conditions) and the conditions after the realization of the naturalistic engineering works described in Section 5. This comparison, considering the results obtained both from deterministic and probabilistic analysis, is introduced in the following paragraphs.

\subsection{Slopes Stability before Countermeasures}

\subsubsection{Deterministic Analyses}

The stability conditions, before the countermeasure realization, have been evaluated considering two limit conditions: (i) dry soil (referred to as $C_{\lim 1}$ ) and (ii) saturated soil $(\mathrm{Sr}=1)$, with piezometric line at the ground surface (referred to as $C_{\lim 2}$ ). For the slopes examined, the results obtained are shown in Figures 12 and 13, respectively. These Figures show the potentially unstable soil volume in green, bounded by the critical slip surface. In the computation, the slip surfaces are assumed circular; the center of the circular slip surface is shown with a point in the graph along with the corresponding value of $F_{s}$. As expected, higher values of $F_{s}$ are obtained considering the dry soil (Figure 12a,b), while values of $F_{S}$ smaller than 1 occur, for both slopes, when the water table is at the ground surface (Figure 13a,b). The obtained results in terms of $F_{s}$ are shown in Table 4.

Table 4. Summary of Fs values obtained for slope 1 (S1) and slope 2 (S2), for the water table conditions considered.

\begin{tabular}{ccc}
\hline Slope & $C_{\text {lim } 1}$ & $C_{\text {lim } 2}$ \\
\hline S1 & 1.569 & 0.804 \\
S2 & 1.548 & 0.806 \\
\hline
\end{tabular}




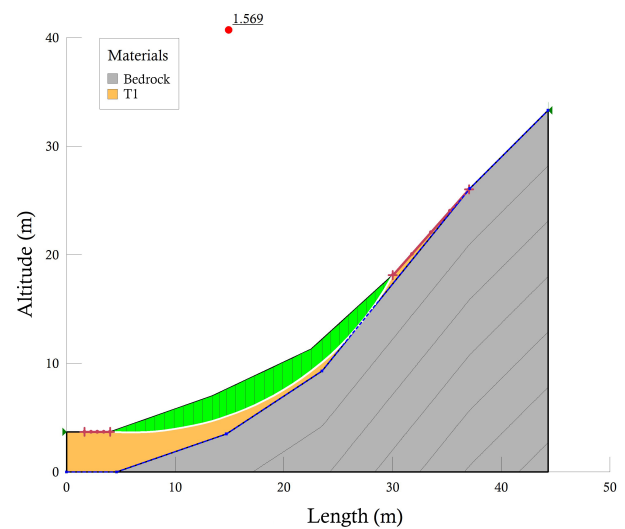

(a)

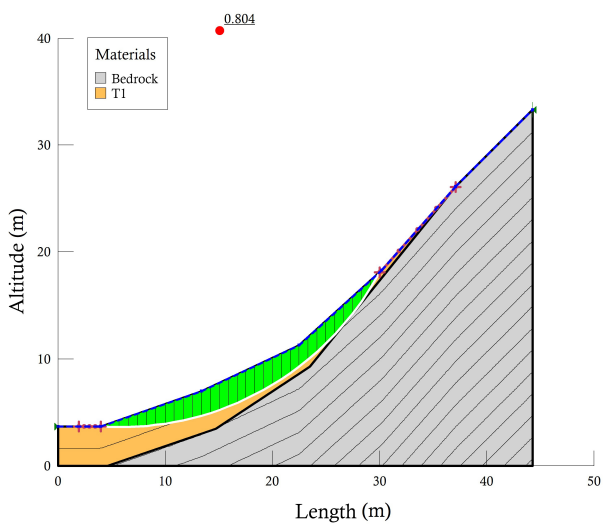

(b)

Figure 12. Deterministic analysis: Slope profile n.1: (a) no water and (b) piezometric line at the ground surface.

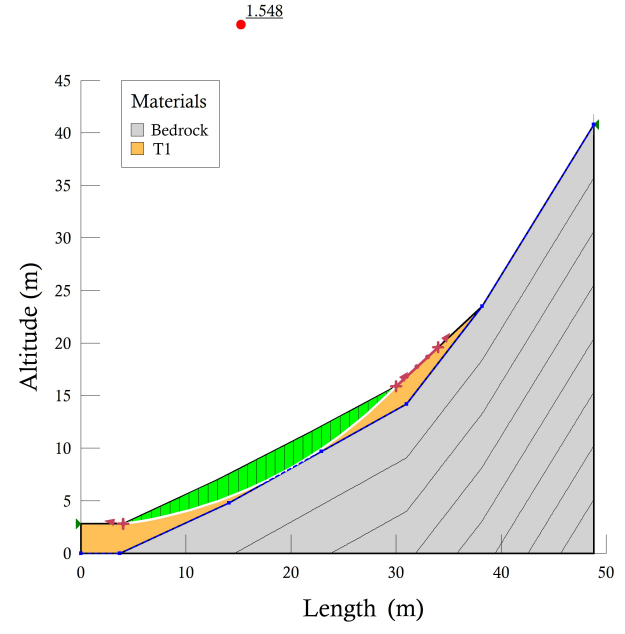

(a)

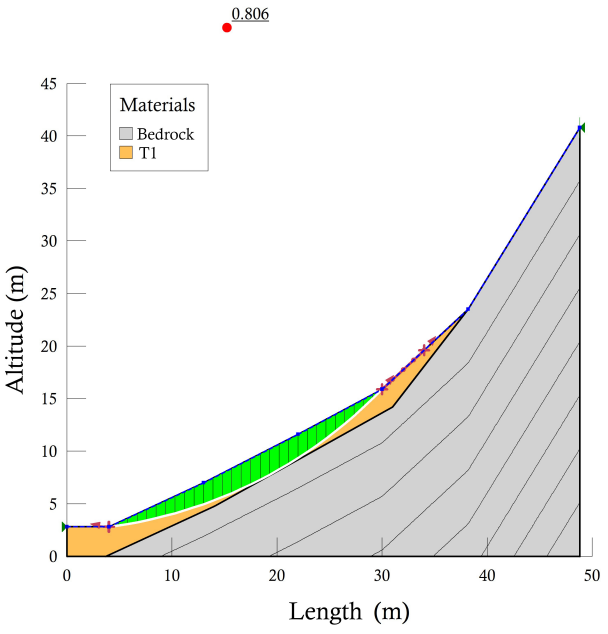

(b)

Figure 13. Deterministic analysis: Slope profile n.2: (a) no water and (b) piezometric line at the ground surface.

\subsubsection{Probabilistic Analyses}

The reliability analysis has been obtained considering a number of Monte Carlo realizations $(\mathrm{N})$ equal to 10,000 , corresponding to a confidence level of $92 \%$, computed according to [17]. The absolute frequency histograms of $F_{S}$ for the two slopes analyzed are shown in Figure 14a,b; the probability density function (PDF) that best fits the experimental data results, for all the analyzed cases, is the normal distribution. 


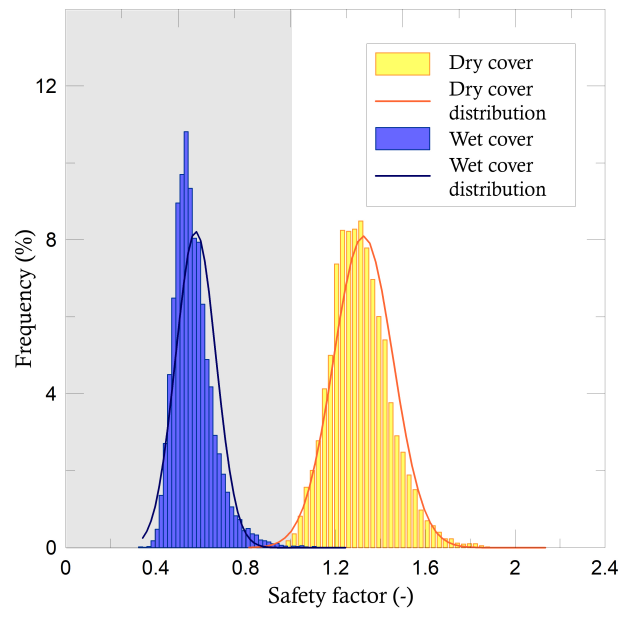

(a)

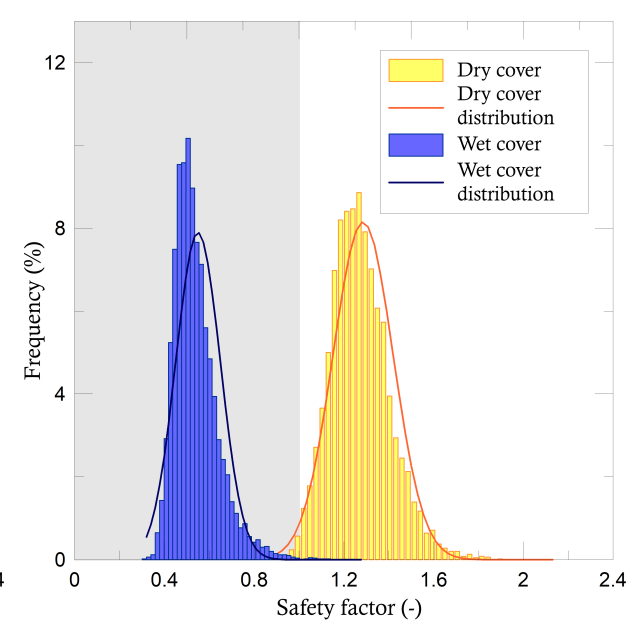

(b)

Figure 14. Results of the probabilistic analysis for the water table conditions considered: (a) slope S1 and (b) slope S2.

The red Gauss curve (Figure 14) refers to the $C_{\lim 1}$ condition, whereas the blue curve describes the $F_{S}$ distribution in the condition of water table at the ground surface $\left(C_{\lim 2}\right)$. The probability of failure, not negligible for both slopes, reaches extremely high values in correspondence of $C_{\lim 2}$. More details on the numerical values obtained are shown in the Table 5 in terms of PoF values.

Table 5. Summary of PoF values obtained for the two water table conditions considered.

\begin{tabular}{ccc}
\hline Slope & $C_{\text {lim } 1}$ & $C_{\text {lim } 2}$ \\
\hline S1 & 0.23 & 0.99 \\
S2 & 0.53 & 0.99 \\
\hline
\end{tabular}

The soil cover analyzed, for both slopes, in absence of water (dry soil) results in stable conditions; instability conditions are generated by intense and prolonged rainfall that cause an increase of the water table, until the limit condition is reached. When the water table reaches the ground surface, both slopes are in limit equilibrium conditions. These considerations, confirmed by deterministic and probabilistic approach used, are in agreement with the observations in situ, where many reactivations of the landslides occur as a result of extreme events.

\subsection{Slopes Stability after the Stabilization Works}

The realization of the naturalistic engineering works produces an increase in the slopes stability conditions. The results obtained from the deterministic approach for the $C_{\lim 2}$ condition are shown in Figure 15. This figure shows the potentially unstable soil volume in green, bounded by the critical slip surface. In the computation, the slip surfaces are assumed circular; the center of the circular slip surface is shown with a point in the graph along with the corresponding value of $F_{s}$. Figure $16 \mathrm{~b}$ shows the histograms of the absolute frequencies of $F_{S}$, obtained as a result of the probabilistic reliability analysis, comparing the three cases considered: dry slope $\left(C_{\lim 1}\right.$-water table at the soil cover bottom $)$ before the works, wet slope $\left(C_{\text {lim } 2}\right.$-water table at the ground surface) before the works and wet slope $\left(C_{\lim 2}\right.$-water table at the ground surface) after the stabilization works. 


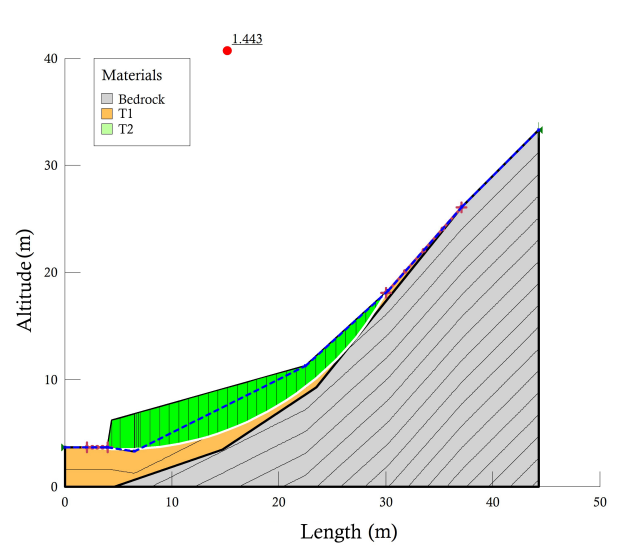

(a)

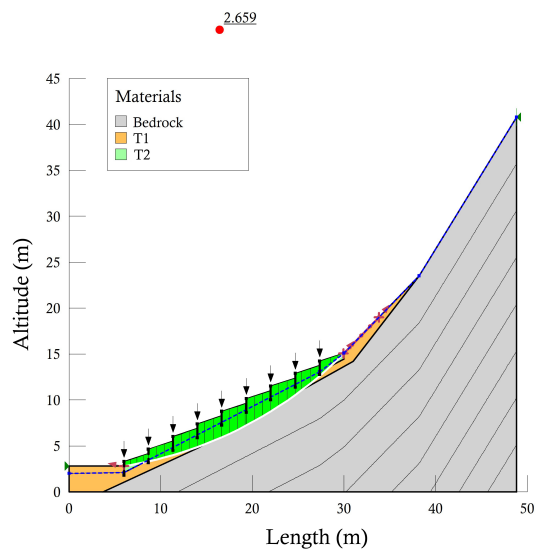

(b)

Figure 15. Stability conditions for S1 (a) and S2 (b), after the stabilization works.

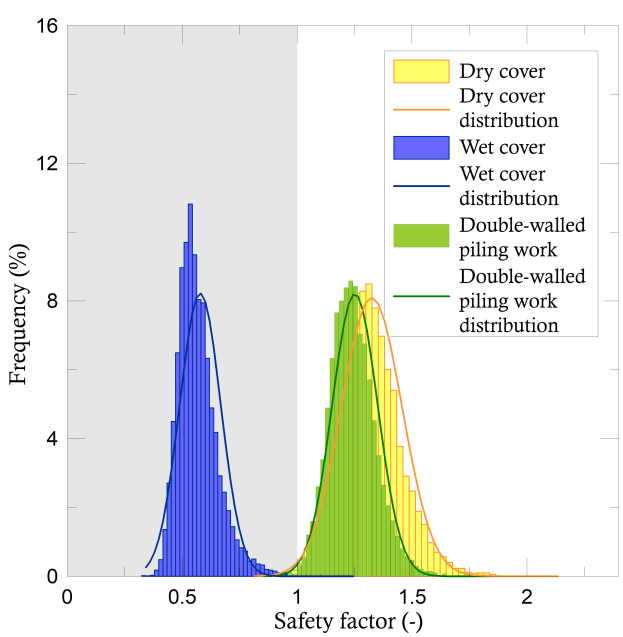

(a)

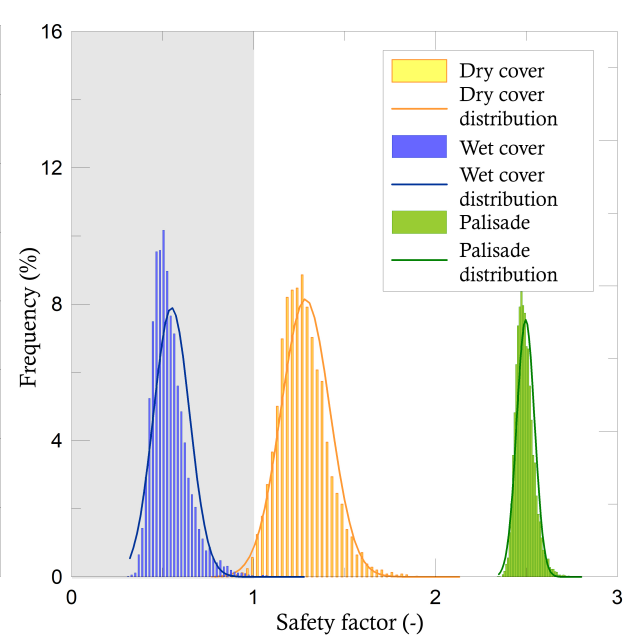

(b)

Figure 16. Distributions of $F_{S}$ obtained from the probabilistic analysis for the slopes $\mathrm{S} 1$ (a) and S2 (b).

With reference to the two approaches used, in Table 6, the results obtained for $C_{l i m 2}$ condition are summarized.

Table 6. Summary of results after the realization of engineering naturalistic works.

\begin{tabular}{ccccc}
\hline Slope & $\boldsymbol{F} \boldsymbol{s}$ & $\boldsymbol{E}_{f s}$ & PoF & $\boldsymbol{\Delta}_{\boldsymbol{P o F}}$ \\
\hline S1 & 1.44 & $79 \%$ & 0.2 & 0.79 \\
S2 & 2.66 & $229 \%$ & 0 & 0.99 \\
\hline
\end{tabular}

Let us define $E_{F S}$ the efficiency of the engineering work, as

$$
E_{F s}(\%)=\frac{F_{s, \text { post }}-F_{s, \text { pre }}}{F_{s, \text { pre }}}
$$

where $F_{s, p o s t}$ represents the safety factor after the countermeasure installation, $F_{s, p r e}$ represents the safety factor in the slope initial condition, and $\Delta_{P o F}$ represents the variation of the probability of failure before and after the works. As for the $F_{S}$ distribution, an average value of $F_{s}$ equal to 1.2 is observed in slope $\mathrm{S} 1$ for the double-walled piling work (Figure 16a), while an average value of $F_{S}$ of $\sim 2.3$ is observed in slope S2, due to the palisade construction (Figure 16b). In conclusion, for the limit 
condition of the water table at the ground surface, the considered countermeasures ensure average values of $F_{S}$ greater than 1 for both slopes. In particular, the PoF is very low for the slope $\mathrm{S} 1$ ( $\mathrm{PoF}=$ 0.2 ) and zero for the slope $S 2$ studied. It can be observed that, as a result of both deterministic and probabilistic approaches, the stabilization work examined in $\mathrm{S} 2$ leads to a greater increase in the safety of the slope: with the deterministic calculations, the efficiency of the engineering work made in S1 is $\sim 79 \%$, whereas the countermeasure to stabilize the slope S2 reaches an efficiency of $\sim 229 \%$. The same behavior can be observed from the results of the probabilistic analyses showing $\Delta_{P o F}$ equal to 0.79 for the work type on slope S1 and $\Delta_{P o F}$ equal to 0.99 for the stabilization work on slope S2.

\section{Conclusions}

In this work, we focused on the analysis of unstable slopes threatening a greenway (a former track of a railway) in central Italy, where numerous shallow landslide reactivations occur after intense or prolonged rainfall. The track is in a valuable area for the environmental and landscape features. Thus, countermeasures based on naturalistic engineering works seem the most appropriate solutions. However, although the design of traditional slope stabilization works is based on computational methods very well-known in the literature and widely tested in practice, the design of naturalistic engineering works is still a relatively open issue, for which there are no commonly accepted methodologies. Anyway, their low cost and low environmental impact encourage the scientific community to develop standardized design procedures. To provide a contribute in this direction, in this paper (i) different countermeasures for two selected study slope have been proposed, and (ii) simplified schematizations for computing the increasing of stability produced by the works considered. To obtain an estimate of the reliability analyses carried out, to the deterministic approach for the $F_{S}$ evaluation, a probabilistic model for PoF estimation was coupled. The last approach allows to consider the uncertainty of the soil mechanical properties, that are described through appropriate probability density functions (PDF). The stabilizing contribution of the considered works has been then quantified by evaluating the increase of the safety conditions (expressed through the safety factor $F_{S}$ and the probability of failure $\mathrm{PoF}$ ) and by estimating the efficiency of the system. For the two study slopes considered, the implementation of the simulated interventions produces a relevant increase of safety level with a very low environmental impact, as showed by the photographic simulation of the installations. The estimates obtained might be improved through laboratory tests to more accurately evaluate the contribution of the roots to soil strength.

Author Contributions: Conceptualization, D.S.; Data curation, L.D.P. and E.C.; Formal analysis, E.V.; Resources, E.C.; Software, L.D.P.; Supervision, D.S.; Writing—original draft, E.V.; Writing—review \& editing, D.S. All authors have read and agreed to the published version of the manuscript.

Funding: This research was funded by the project PRIN2015.

Acknowledgments: This work has been carried out in the framework of the project PRIN2015: "Innovative monitoring and design strategies for sustainable landslide risk mitigation." The authors wish to thank Giulia Felicioni, Responsible of the Office "Landslide Risk-Umbria Region", for the support and for provinding input data for the study area. The authors would also like to thank Umbriamobilità for providing technical reports and other historical information on the path.

Conflicts of Interest: The authors declare no conflict of interest.

\section{References}

1. Haque, U.; Silva, P.; Devoli, G.; Pilz, J.; Zhao, B.; Khaloua, A.; Wilopo, W.; Andersen, P.; Lu, P.; Lee, J.; et al. The human cost of global warming: Deadly landslides and their triggers (1995-2014). Sci. Total Environ. 2019, 682, 673-684. [CrossRef] [PubMed]

2. Gariano, S.; Melillo, M.; Peruccacci, S.; Brunetti, M.T. How much does the rainfall temporal resolution affect rainfall thresholds for landslide triggering? Nat. Hazards 2020, 100, 655-670. [CrossRef]

3. Morgan, R.P.; Rickson, R.J. Slope Stabilization and Erosion Control: A Bioengineering Approach; Taylor \& Francis: Abingdon, UK, 2003. 
4. Waldron, L. The shear resistance of root-permeated homogeneous and stratified soil 1. Soil Sci. Soc. Am. J. 1977, 41, 843-849. [CrossRef]

5. Wu, T.H.; McKinnell, W.P., III; Swanston, D.N. Strength of tree roots and landslides on Prince of Wales Island, Alaska. Can. Geotech. J. 1979, 16, 19-33. [CrossRef]

6. Operstein, V.; Frydman, S. The influence of vegetation on soil strength. Proc. Inst. Civ.-Eng.-Ground Improv. 2000, 4, 81-89. [CrossRef]

7. Stokes, A.; Atger, C.; Bengough, A.G.; Fourcaud, T.; Sidle, R.C. Desirable plant root traits for protecting natural and engineered slopes against landslides. Plant Soil 2009, 324, 1-30. [CrossRef]

8. Cecconi, M.; Pane, V.; Napoli, P.; Cattoni, E. Deep roots planting for surface slope protection. Electron. J. Geotech. Eng. U 2012, 17, 2809-2820.

9. Wu, T.H. Root reinforcement of soil: Review of analytical models, test results, and applications to design. Can. Geotech. J. 2013, 50, 259-274. [CrossRef]

10. Cazzuffi, D.; Corneo, A.; Crippa, E. Slope stabilisation by perennial "gramineae" in Southern Italy: Plant growth and temporal performance. Geotech. Geol. Eng. 2006, 24, 429-447. [CrossRef]

11. Norris, J.; Greenwood, J.R. Assessing the role of vegetation on soil slopes in urban areas. In Proceedings of the 10th IAEG International Congress, Nottingham, UK, 6-10 September 2006.

12. Calcaterra, D.; Palma, B.; Doronzo, G.; de Luca Tupputi, F. L'uso delle tecniche di Ingegneria Naturalistica nella mitigazione del rischio da frana: Alcuni esempi dalla Campania. Quad. Geol. Appl. 2004, 11, 2.

13. Zarotti, C. L'interazione pendio atmosfera: Piante erbacee a radicazione profonda per la protezione dei versanti in caso di fenomeni meteorologici intensi. In Proceedings of the XXV Convegno Nazionale di Geotecnica: La geotecnica nella difesa del territorio e delle infrastrutture dalle calamità naturali, Baveno, Italy, 4-6 June 2014.

14. Raia, S.; Alvioli, M.; Rossi, M.; Baum, R.; Godt, J.; Guzzetti, F. Improving predictive power of physically based rainfall-induced shallow landslide models: A probabilistic approach. arXiv 2014, arXiv:13054803 .

15. Salciarini, D.; Fanelli, G.; Tamagnini, C. A probabilistic model for rainfall—Induced shallow landslide prediction at the regional scale. Landslides 2017, 14, 1731-1746. [CrossRef]

16. Salciarini, D.; Volpe, E.; Cattoni, E. Probabilistic vs. Deterministic Approach in Landslide Triggering Prediction at Large-scale. In Proceedings of the National Conference of the Researchers of Geotechnical Engineering, Lecco, Italy, 3-5 July 2019; Springer: Berlin/Heidelberg, Germany, 2019; pp. 62-70.

17. Harr, M.E. Reliability-Based Design in Civil Engineering; McGraw-Hill: New York, NY, USA, 1987.

18. Fanelli, G.; Salciarini, D.; Tamagnini, C. Reliable Soil Property Maps over Large Areas: A Case Study in Central Italy. Environ. Eng. Geosci. 2016, 22, 37-52. [CrossRef]

19. Istituto Superiore per la Protezione e Ricerca Ambientale. IFFI_Inventario dei Fenomeni Franosi in Italia, Web Map Service; Istituto Superiore per la Protezione e Ricerca Ambientale: Rome, Italy, 2018.

20. Sezione Rischio Geologico da Frana della Regione Umbria. Mappa di suscettibilita'; Sezione Rischio Geologico da Frana della Regione Umbria: Perugia, Italy, 2018.

21. Zhang, S.; Zhang, X.; Pei, X.; Wang, S.; Huang, R.; Xu, Q.; Wang, Z. Model test study on the hydrological mechanisms and early warning thresholds for loess fill slope failure induced by rainfall. Eng. Geol. 2019, 258, 105135. [CrossRef]

22. Peruccacci, S.; Brunetti, M.; Gariano, S.; Melillo, M.; Rossi, M.; Guzzetti, F. Rainfall thresholds for possible landslide occurence in Italy. Geomorphology 2017, 290, 39-57. [CrossRef]

23. Frangioni, A. Relazione Geologica; Technical Report; Perugia, Italy. Unpublished work, 2014.

24. Federici, G.; Pompili, S.; Ranocchia Cuttini, D. Rilievo delle criticità sul tracciato dell'ex ferrovia Spoleto-Norcia; Technical Report; Perugia, Italy. Unpublished work, 2017.

25. Baecher, G.B.; Christian, J.T. Reliability and Statistics in Geotechnical Engineering; John Wiley \& Sons: Hoboken, NJ, USA, 2005.

26. GEO-SLOPE International Ltd. Stability Modeling with GeoStudio; GEO-SLOPE International Ltd.: Calgary, AB, Canada, 2019.

27. Morgenstern, N.; Price, V. The Analysis of the Stability of General Slip Surfaces. Geotechnique 1965, 15, 79-93. [CrossRef] 
28. Salciarini, D.; Godt, J.; Savage, W.Z.; Conversini, P.; Baum, R.; Michael, J.A. Modeling regional initiation of rainfall-induced shallow landslides in the eastern Umbria Region of central Italy. Landslides 2006, 3, 181. [CrossRef]

29. Salciarini, D.; Tamagnini, C.; Ronchi, F.; Volpe, E.; Fanelli, G. An approach for large-scale soil characterization for the application of non-structural landslide risk mitigation. Rivista Italiana di Geotecnica 2017, 51, 7-21. 